\title{
Up-regulation of peroxiredoxin 3 by high-risk human papillomavirus in cervical cancer cells
}

\section{Type}

Research paper

\section{Keywords}

cervical cancer, Oxidative stress, reactive oxygen species, human papillomavirus, peroxiredoxin

\begin{abstract}
Introduction

Peroxiredoxin $3(\mathrm{PRX} 3)$ is a member of PRX family with antioxidant functions by scavenging hydrogen peroxide. Since the development of cervical cancer is causally linked to high-risk human papillomavirus (HPV) that induces oxidative stress, we conducted the present study to investigate the response of PRX3 to high-risk HPV infection.
\end{abstract}

Material and methods

This study included fifty-six patients with invasive squamous cervical cancer and sixty control patients with hysteromyoma. Enzyme-linked immunosorbent assay was performed to detect cervical oxidative stress and serum PRX3. The expression of PRX3 and oncoprotein E6 of HPV16 or HPV18 was examined in cervical cancer tissues by immunohistochemistry. Western Blot was applied to detect the expression of PRX3 and E6 in cervical cancer cell lines including CaSki, HeLa, and C33A.

\section{Results}

Patients with cervical cancer showed higher serum PRX3 than control patients with hysteromyoma. Levels of oxidative markers in cervical cancer tissues were elevated as compared to normal cervical epithelia. PRX3 expression was upregulated in cervical cancer tissues and the upregulation was positively associated with the expression of E6 of HPV16 or HPV18. The association was confirmed in HPV-containing cervical cancer cell lines including CaSki and HeLa.

\section{Conclusions}

Our results indicated a positive response of PRX3 to HPV-induced oxidative stress. Serum PRX3 might be a potential indicator of active amplification of high-risk HPV in cervical cancer cells. 


\section{Abstract}

Introduction

Peroxiredoxin 3 (PRX3) is a member of PRX family with antioxidant functions by scavenging hydrogen peroxide. Since the development of cervical cancer is causally linked to high-risk human papillomavirus (HPV) that induces oxidative stress, we conducted the present study to investigate the response of PRX3 to high-risk HPV infection.

Material and methods

This study included fifty-six patients with invasive squamous cervical cancer and sixty control patients with hysteromyoma. Enzyme-linked immunosorbent assay was performed to detect cervical oxidative stress and serum PRX3. The expression of PRX3 and oncoprotein E6 of HPV16 or HPV18 was examined in cervical cancer tissues by immunohistochemistry. Western Blot was applied to detect the expression of PRX3 and E6 in cervical cancer cell lines including CaSki, HeLa, and C33A.

Results

Patients with cervical cancer showed higher serum PRX3 than control patients with hysteromyoma. Levels of oxidative markers in cervical cancer tissues were elevated as compared to normal cervical epithelia. PRX3 expression was upregulated in cervical cancer tissues and the upregulation was positively associated with the expression of E6 of HPV16 or HPV18. The association was confirmed in HPV-containing cervical cancer cell lines including CaSki and HeLa.

\section{Conclusion}

Our results indicated a positive response of PRX3 to HPV-induced oxidative stress. Serum PRX3 might be a potential indicator of active amplification of high-risk HPV in cervical cancer cells.

Key words: cervical cancer, human papillomavirus, oxidative stress, peroxiredoxin, reactive oxygen species 


\section{Introduction}

As a kind of antioxidant enzyme, peroxiredoxin 3 (PRX3) is mainly located in mitochondria and reduces hydrogen peroxide into water with its two cysteines. By controlling mitochondrial reactive oxygen species (ROS), PRX3 is involved in diverse cellular processes such as growth, differentiation, apoptosis, and malignancy[1-3]. According to previous reports, the expression of PRX3 was upregulated in cervical cancer[4, 5]. Strong cytoplasmic staining of PRX3 was observed in the surrounded cells of cervical cancer nests, which was consistent with the pattern of Ki67 as a marker of active cell proliferation[5]. However, the precise mechanism for the upregulation of PRX3 has not been well known.

The development of cervical cancer is causally linked to high-risk human papillomavirus (HR-HPV), and the integration of HPV oncogenes (e.g. E6 and E7) into the genome of host cells is considered to be a key step towards carcinogenesis. Previous studies indicated that oxidative stress was involved in the integration process. The oncogenes of HR-HPV induced ROS production and subsequent DNA damage of host cells, promoting genomic instability of the cells and the integration of HPV DNA[6, 7]. In addition, an increase in oxidative DNA damage facilitated HPV genome amplification in cancer cells[8]. Since alteration of PRX3 was involved in the persistent HPV infection and cervical carcinogenesis[9], the present study was conducted to investigate the link between PRX3 and HR-HPV in cervical cancer.

\section{Materials and methods}

\section{Patients and samples}

This study was approved by the Ethics Committee of Yantai Affiliated Hospital of Binzhou Medical University (No. 2017-007R) and was conducted between October 2017 and December 2019. After informed consent from all patients, we collected blood samples from patients with squamous cervical cancer three days before and after operation respectively. Samples from patients with hysteromyoma were collected at the same time and were used as controls. General information including age, body mass index (BMI), and blood pressure (BP) were recorded before blood sampling. Fasting blood sugar (FBS), fasting insulin (FINS), total cholesterol (TC), and triglyceride (TG) were routinely examined on the blood.

\section{Examination of HPV infection in cervices}

Status of HPV infection in cervical tissues was examined by HPV genoarray test kit (Hybribio 
Company, Hong Kong, China). Briefly, DNA was extracted from cervical tissues and amplified by PCR. The PCR products were then hybridized on HPV genoarray membrane that contained probes corresponding to $23 \mathrm{HPV}$ subtypes (HR-HPVs: 16、18、31、33、35、39、45、51、52、53、56、 58、59、66、68、73、82; low-risk HPVs: 6、11、42、43、81、83). Biotin was used as positive control and distilled water as negative control. The membrane was visualized through NBT/BCIP to determine the status of HPV infection.

\section{Detection of oxidative markers in cervices}

Oxidative makers including oxidative DNA adduct 8-hydroxy-2'-deoxyguanosine (8-OHdG) and glycoxidation product carboxymethyl lysine (CML) were detected in cervical cancer tissues and control samples by enzyme-linked immunosorbent assay (ELISA). The Highly Sensitive 8OHdG ELISA kit was purchased from Japan Institute for the Control of Aging (Fukuroi 437-0122, Japan), and the Human CML ELISA kit was purchased from Kamiya Biomedical Company (Seattle, WA 98168 USA). For $8 \mathrm{OHdG}$ detection, DNA was extracted from tissues and digested in distilled water. $50 \mu 1$ of sample or standard and $50 \mu 1$ of primary antibody were added to each well. After fully mixing, the plates were covered and incubated at $4^{\circ} \mathrm{C}$ for overnight. The contents of the plates were poured off and the plates were washed thoroughly. $100 \mu 1$ of secondary antibody was added to each well and incubated at room temperature for $1 \mathrm{~h}$. The contents of the plates were poured off and the plates were washed thoroughly. $100 \mu 1$ of the reconstituted enzyme substrate was added to each well and incubated at room temperature for $15 \mathrm{~min}$. Finally, $100 \mu \mathrm{l}$ of the reaction terminating solution was added and the absorbance was read at $450 \mathrm{~nm}$. The amount of $8 \mathrm{OHdG}$ in each sample was determined using a standard curve by plotting absorbance vs. concentration of standards. For CML detection, tissues were rinsed in ice-cold PBS to remove excess blood and weighed before homogenization. The homogenates were centrifuged for 15 minutes at $1500 \times \mathrm{g}$. and the supernatants were used for the assay. $100 \mu \mathrm{l}$ of calibrators or samples were added to each well of the antibody pre-coated plate, and $100 \mu \mathrm{l}$ of PBS was added to the blank control well. $10 \mu \mathrm{l}$ of balance solution was dispensed into $100 \mu \mathrm{l}$ specimens and mixed thoroughly. $50 \mu \mathrm{l}$ of conjugate was added to each well (except blank control well) and incubated at $37^{\circ} \mathrm{C}$ for $1 \mathrm{~h}$. After removal of incubation mixture and washing for five times, $50 \mu \mathrm{l}$ Substrate A and $50 \mu \mathrm{l} \mathrm{Substrate} \mathrm{B} \mathrm{were} \mathrm{added} \mathrm{to} \mathrm{each} \mathrm{well.} \mathrm{After} \mathrm{incubation} \mathrm{at} 37^{\circ} \mathrm{C}$ for $15 \mathrm{~min}, 50 \mu 1$ of stop solution was added to each well and the absorbance was read at $450 \mathrm{~nm}$. A calibration curve 
was constructed by plotting the average absorbance for each calibrator on the horizontal (X) axis against the concentration on the vertical $(\mathrm{Y})$ axis, and the concentration of samples was calculated from the calibration curve.

\section{Detection of serum PRX3}

Blood samples from the subjects were centrifuged at $1500 \times g$ and $4^{\circ} \mathrm{C}$ for $10 \mathrm{~min}$ for serum separation. We performed ELISA to detect serum PRX3 by following the manufacturer's instruction (NeoScientific Company, Cambridge, MA, USA). Except for the pre-treatment of samples, the detection procedure was basically same as described in the above section. Each sample was assayed in triplicate and measured at the absorbance of $450 \mathrm{~nm}$ on a spectrophotometer.

\section{Immunohistochemistry}

The cervical tissues were processed to be formalin-fixed and paraffin-embedded blocks. Slides were incubated with mouse monoclonal antibodies against human PRX3 and E6 of HPV16 or HPV18 respectively (1:1000 dilution according to the suggestion of manufacturer Abcam Company at Cambridge, UK). Immunostaining scores were evaluated by two pathologists according to the product of positive cell percentage and staining intensity: $<5 \%=0,5 \% \sim 20 \%=1,21 \% \sim 50 \%=2$, $51 \% \sim 75 \%=3,>75 \%=4$; no color $=0$, light yellow $=1$, yellow=2, deep yellow=3.

\section{Detection of PRX3 and E6 expression in cervical cancer cell lines}

Cervical cancer cell lines including CaSki, HeLa, and C33A were purchased from the Cell Bank of Chinese Academy of Sciences (Shanghai, China). These cells were cultured at $37^{\circ} \mathrm{C}$ in a humidified incubator with $5 \% \mathrm{CO}_{2}$ and were passaged at a 1:4 split ratio. Cells at passage 3 were re-cultured in six-well plates with a density of $1 \times 10^{6}$ cells $/ \mathrm{ml}$. Seventy-two hours later, total protein was extracted from the cells to detect the expression of PRX3 and E6 of HPV16 or HPV18 respectively by Western Blot (WB). The primary antibodies against PRX3 and E6 were purchased from Abcam Company (Cambridge, UK). GAPDH was used as internal control. Cells from each well of the culture plate were considered as one sample and we detected twelve samples for each cell line. The intensities of the signals were analyzed with a Gel-Pro Analyzer and presented as integrated optical density (IOD).

\section{Statistic analysis}

Serum PRX3 was compared by $t$ test. Analysis of variance was used to compare the expression of 
PRX3 and E6 in cervical cancer cell lines, while Pearson's correlation coefficient was applied to analyze the association between the expression of PRX3 and E6. $P<0.05$ was considered to be statistically significant.

\section{Results}

In the present study, we included fifth-six patients with invasive squamous cervical cancer and sixty control subjects with hysteromyoma. The FIGO stages of the cancer patients were 39 for stage I and 17 for stage II respectively, among which 10 cases showed cancer-positive in pelvic lymph nodes. The patients did not receive chemotherapy or radiotherapy before operation. As indicated in Table 1, there was no significant difference between cancer patients and controls in relation to age, BMI, BP, FBS, FINS, TC, and TG.

\section{Status of HPV infection and oxidative stress in cervical cancer patients}

As determined by HPV genoarray test kit, all the tumor samples were infected with HR-HPVs, among which forty-eight samples were positive for HPV16, four samples were positive for HPV18, and four samples were positive for HPV33. No relationship was found between HPV infection and BMI. All of the control patients were negative for HPVs. The levels of $8-\mathrm{OHdG}$ were $7.5 \pm 1.2 \mathrm{ng} / \mathrm{ml}$ in cancer tissues and $2.9 \pm 0.3 \mathrm{ng} / \mathrm{ml}$ in controls (cancer vs. control: $t=8.20, P<0.001$ ), while the levels of CML were $116.9 \pm 5.7 \mu \mathrm{g} / \mathrm{ml}$ in cancer tissues and $52.5 \pm 4.3 \mu \mathrm{g} / \mathrm{ml}$ in controls (cancer vs. control: $t=10.89$, $P<0.001)$.

\section{Serum levels of PRX3 in cervical cancer patients}

We performed ELISA to detect the levels of serum PRX3 in cervical cancer patients and controls with hysteromyoma. Pre-operative serum PRX3 was $30.2 \pm 4.6 \mathrm{ng} / \mathrm{ml}$ in cervical cancer patients and $14.6 \pm 2.1 \mathrm{ng} / \mathrm{ml}$ in controls respectively (cancer patients vs. controls: $t=2.320, P=0.026$ ). Further analysis showed higher serum PRX3 in node positive patients than in negative cases $(t=2.110$, $P=0.035$ ). Interestingly, serum levels of PRX3 in cancer patients decreased to $17.0 \pm 1.3 \mathrm{ng} / \mathrm{ml}$ three days after operation, which was comparable to that of control patients $(15.3 \pm 1.1 \mathrm{ng} / \mathrm{ml})$. In addition, we did not notice significant association between serum PRX3 and clinical or biochemical parameters including BMI, BP, FBS, FINS, TC, and TG (data not shown).

\section{Expression of PRX3 and E6 of HPV16 or HPV18 in cervical cancer tissues}

As shown in Fig. 1A and 1B, PRX3 was extensively expressed in the cytoplasm of normal cervical epithelia, but the staining intensity was much weak as compared to that of cervical cancer cells. The 
immunostaining score was $3.6 \pm 0.9$ in normal cervical epitheliums and $10.6 \pm 1.4$ in cancer cells $(F=$ 2.819, $P=0.000$ ). In addition, the E6 of HPV16 or HPV18 was expressed in nearly all cervical cancer cells as illustrated in Fig. 1D and 1F respectively. The staining intensity for HPV18 E6 was slightly weaker than that of HPV16 E6, but the immunostaining scores did not reach significant difference between the two subtypes. Pearson's correlation analysis showed positive association between the expression of PRX3 and HPV16 E6 ( $\mathrm{r}=0.532, \mathrm{P}=0.031)$ or HPV18 E6 ( $\mathrm{r}=0.515, \mathrm{P}=0.041)$. The staining scores of either PRX3 or HPV16 E6 were not associated with clinicopathologic parameters including stage, cell grade, and lymph nodes (Table 2).

\section{Expression of PRX3 and E6 of HPV16/HPV18 in cervical cancer cell lines}

To confirm the association between HPV amplification and PRX3 expression, we detected the expression of PRX3 and E6 of HPV16/HPV18 in cervical cancer cell lines, including CaSki, HeLa, and C33A. As indicated in Fig. 2A and 2B, the expression of PRX3 was significantly increased in HR-HPV-containing cells (CaSki and HeLa) as compared to that in HPV-negative C33A cells. Fig. 2C shows the mean IOD values of PRX3 and HPV16/HPV18 E6 in each cancer cell line. In addition, the expression of PRX3 was positively associated with that of E6 of HPV16 $(r=0.651, P=0.027)$ or HPV18 $(r=0.560, P=0.031)$.

\section{Discussion}

In the present study, we demonstrated upregulation of PRX3 by HR-HPV in cervical cancer cells, suggesting an important role of PRX3 in the response to HR-HPV induced oxidative stress. Since the serum PRX3 was increased in cervical cancer patients, we suppose that serum PRX3 might be a potential indicator of HR-HPV amplification.

The production of ROS is increased because of active proliferation of cervical cancer cells [10]. An other factor that contributes to the ROS production might be the amplification of HR-HPV [11], which induces oxidative stress as indicated in the present study. Increased ROS production and development of oxidative stress lead to oxidation of proteins and peroxidation of membrane lipids [12]. By review of previous literatures, we suppose that the upregulation of PRX3 might be the transcriptional regulation by genes including c-Myc, nuclear factor E2-related factor 2 (Nrf2), forkhead box transcription factors FOXO3A or FOXM1, and small non-coding microRNAs (miRNAs). According to previous reports, infection with HPV16 is tightly associated with c-Myc amplification [13, 14], 
which plays an important role in cervical cancer development and progression [15]. Since PRX3 is a downstream target of c-Myc [3], the interaction of c-Myc and PRX3 might be a candidate pathway for the upregulation of PRX3. In lung squamous cell carcinoma, PRX3 is over-expressed in an Nrf2 dependent manner, which indicates a potentially important role of the Nrf2-PRX3 pathway in the tumor [16]. Chiribau et al. reported that FOXO3A mediated PRX3 expression resulting in the resistance to oxidative stress in human cardiac fibroblasts [17], which was confirmed by other researchers in pheochromocytoma cells, cardiac cells, and endothelial cells respectively [18-20]. In addition, a study conducted by Cunniff et al. reported the co-existence of cytoplasmic FOXM1 and mitochondrial PRX3 in mesothelioma cells [21]. In endometrial cancer stem cells, increased expression of PRX3 was induced by FOXM1 for the maintenance of mitochondrial function and cell survival [22]. MicroRNAs (miRNAs) are a class of small non-protein-coding molecules. Up to now, miR-23b and miR-383 have been reported to control cell growth and cancer progression by negatively regulating PRX3 expression in several types of solid tumors [23, 24].

The serum levels of PRX3 in cancer patients have been investigated in recent years. For example, serum PRX3 is significantly higher in patients with hepatocellular carcinoma and could be used as a biomarker for the diagnosis and prognosis of the disease $[25,26]$. However, the alteration of serum PRX3 in cervical cancer patients has not been reported up to now. Here we presented an increase of serum PRX3 in cervical cancer patients, especially in patients with cancer-positive lymph nodes. The serum PRX3 had no significant association with either the staining scores of PRX3 in cancer tissues or clinicopathologic features of patients, which was different from that in patients with hepatocellular carcinoma $[25,26]$. The biological characteristics of cervical cancer are quite different from that of hepatocellular carcinoma. Cancer cells in cervix grow locally and invade mainly the surrounding tissues or organs. Patients in the present study were at stages I and II in which distant metastasis was absent. On the contrary, liver is an organ with abundant blood supply and blood-based metastasis is a common occurrence in hepatocellular carcinoma. Therefore, the oxidative stress in liver cancer can be reflected in circulating blood. In the present study, we did not find significant association between serum PRX3 and biochemical parameters such as FBS and FINS. The present results were consistent with our previous reports that PRX3 responded mainly to oxidative stress induced by rapid increase of glucose and insulin [27, 28].

In summary, we demonstrated the link between PRX3 and HR-HPV in cervical cancer cells. 
Upregulation of PRX3 reflects a positive response of PRX3 to the oxidative stress in cervical cancer cells induced by HR-HPV amplification and cell growth. Further studies are needed to elucidate the underlying mechanism for the interaction between PRX3 and HR-HPV.

\section{Statement of Ethics}

This study was approved by the Ethics Committee of Yantai Affiliated Hospital of Binzhou Medical University. The reference number is $2017-007 \mathrm{R}$ and the date of approval is 2017-9-26. Informed consent was obtained from all individual participants included in the study.

\section{Disclosure Statement}

The authors have no conflicts of interest to declare.

\section{Acknowledgments}

Hou-Li Liu and Xiao-Juan Sun contributed equally to this work.

This study was supported by Shandong Provincial Natural Science Foundation of China. (ZR2015HL090)

\section{Author Contributions}

Liu HL detected the status of HPV infection in cervical tissues, performed statistic analysis of the results, and prepared the manuscript. Sun XJ compared the oxidative state between cervical cancer tissues and normal cervices, performed statistic analysis of the results, and prepared the manuscript. Li X performed ELISA to detect serum PRX3 of the subjects, and performed WB to detect the expression of PRX3 and E6 of HPV16 or HPV18 in cervical cancer cell lines. Li J performed immunohistochemistry to detect the expression of PRX3 and E6 of HPV16 or HPV18. Bai X gave overall suggestion of the study and critical review of the manuscript. Li L contributed to the design of the experiments, analysis of the results, and preparation of the manuscript.

\section{References}

[1] Matsushima S, Ide T, Yamato M, Matsusaka H, Hattori F, Ikeuchi M, Kubota T, Sunagawa K, Hasegawa Y, Kurihara T, Oikawa S, Kinugawa S, Tsutsui H. Overexpression of mitochondrial peroxiredoxin-3 prevents left ventricular remodeling and failure after myocardial infarction in mice. Circulation. 2006;113:1779-1786.

[2] Chua PJ, Lee EH, Yu Y, Yip GW, Tan PH, Bay BH. Silencing the Peroxiredoxin III gene inhibits cell proliferation in breast cancer.Int J Oncol. 2010;36:359-364.

[3] Wonsey DR, Zeller KI, Dang CV. The c-Myc target gene PRDX3 is required for mitochondrial 
homeostasis and neoplastic transformation. Proc Natl Acad Sci USA. 2002;99:6649-6654.

[4] Kim K, Yu M, Han S, Oh I, Choi YJ, Kim S, Yoon K, Jung M, Choe W. Expression of human peroxiredoxin isoforms in response to cervical carcinogenesis. Oncol Rep. 2009;21:1391-1396.

[5] Hu JX, Gao Q, Li L. Peroxiredoxin 3 is a novel marker for cell proliferation in cervical cancer. Biomed Rep. 2013;1:228-230.

[6] Williams VM, Filippova M, Filippov V, Payne KJ, Duerksen-Hughes P. Human papillomavirus type 16 E6* induces oxidative stress and DNA damage. J Virol. 2014;88:6751-6761.

[7] Chen Wongworawat Y, Filippova M, Williams VM, Filippov V, Duerksen-Hughes PJ. Chronic oxidative stress increases the integration frequency of foreign DNA and human papillomavirus 16 in human keratinocytes. Am J Cancer Res. 2016;6:764-780.

[8] Marullo R, Werner E, Zhang H, Chen GZ, Shin DM, Doetsch PW. HPV16 E6 and E7 proteins induce a chronic oxidative stress response via NOX2 that causes genomic instability and increased susceptibility to DNA damage in head and neck cancer cells. Carcinogenesis, 2015;36:1397-1406.

[9] Safaeian M, Hildesheim A, Gonzalez P, Yu K, Porras C, Li Q, Rodriguez AC, Sherman ME, Schiffman M, Wacholder S, Burk R, Herrero R, Burdette L, Chanock SJ, Wang SS. Single nucleotide polymorphisms in the PRDX3 and RPS19 and risk of HPV persistence and cervical precancer/cancer. PLoS One. 2012, 7: e33619.

[10] Li L, Zhang YG, Chen CL. Anti-apoptotic role of peroxiredoxin III in cervical cancer cells. FEBS Open Bio. 2013;3:51-54.

[11] Lewitowicz P, Nasierowska-Guttmejer A, Rokita W, Adamczyk-Gruszka O, Gluszek S, Chrapek M, Kolos M, Wrona-Cyranowska A, Misiek M. HPV genotyping and p16/Ki-67 test significantly improve detection rate of high-grade cervical squamous intraepithelial lesion. Arch Med Sci. 2019, 16(1):87-93.

[12] Kaczmarczyk-Sedlak I, Folwarczna J, Sedlak L, Zych M, Wojnar W, Szumińska I, Wyględowska-Promieńska D, Mrukwa-Kominek E. Effect of caffeine on biomarkers of oxidative stress in lenses of rats with streptozotocin-induced diabetes. Arch Med Sci. 2019, 15(4): 1073-1080.

[13] Abba MC, Laguens RM, Dulout FN, Golijow CD. The c-myc activation in cervical carcinomas and HPV 16 infections. Mutat Res. 2004;557:151-158.

[14] Veldman T, Liu X, Yuan H, Schlegel R. Human papillomavirus E6 and Myc proteins associate in 
vivo and bind to and cooperatively activate the telomerase reverse transcriptase promoter. Proc Natl Acad Sci USA. 2003;100:8211-8216.

[15] McMurray HR, McCance DJ. Human papillomavirus type 16 E6 activates TERT gene transcription through induction of c-Myc and release of USF-mediated repression. J Virol. 2003;77:9852-9861.

[16] Kim YS, Lee HL, Lee KB, Park JH, Chung WY, Lee KS, Sheen SS, Park KJ, Hwang SC. Nuclear factor E2-related factor 2 dependent overexpression of sulfiredoxin and peroxiredoxin III in human lung cancer. Korean J Intern Med. 2011, 26(3): 304-313.

[17] Chiribau CB, Cheng L, Cucoranu IC, Yu YS, Clempus RE, Sorescu D. FOXO3A regulates peroxiredoxin III expression in human cardiac fibroblasts. J Biol Chem. 2008;283:8211-8217.

[18] Jeong HJ, Jeong HW, Song SS, Kang JW, Seo JH, Lee YH, Lee KS, Kim DW. Upregulation of peroxiredeoxin III in the hippocampus of acute immobilization stress model rats and the Foxo3a-dependent expression in PC12 cells. Cell Mol Neurobiol. 2011, 31: 1041-1046.

[19] Olmos Y, Sanchez-Gomez FJ, Wild B, Garcia-Quintans N, Cabezudo S, Lamas S, Monsalve M. SirT1 regulation of antioxidant genes is dependent on the formation of a FoxO3a/PGC-1alpha complex. Antioxidants \& redox signaling. 2013, 19: 1507-1521.

[20] Liu MH, Zhang Y, He J, Tan TP, Wu SJ, Fu HY, Chen YD, Liu J, LE QF, Hu HJ, Yuan C, Lin XL. Upregulation of peroxiredoxin III in doxorubicin-induced cytotoxicity and the FoxO3a-dependent expression in H9c2 cardiac cells. Exp Ther Med. 2015, 10(4): 1515-1520.

[21] Cunniff B, Benson K, Stumpff J, Newick K, Held P, Taatjes D, Joseph J, Kalyanaraman B, Heintz NH. Mitochondrial-targeted nitroxides disrupt mitochondrial architecture and inhibit expression of peroxiredoxin 3 and FOXM1 in malignant mesothelioma cells. J Cell Physiol. 2013, 228: 835-845.

[22] Song IS, Jeong YJ, Seo YJ, Byun JM, Kim YN, Jeong DH, Han J, Kim KT, Jang SW. Peroxiredoxin 3 maintains the survival of endometrial cancer stem cells by regulating oxidative stress. Oncotarget. 2017, 8(54): 92788-92800.

[23] He HC, Zhu JG, Chen XB, Chen SM, Han ZD, Dai QS, Ling XH, Fu X, Lin ZY, Deng YH, Qin GQ, Cai C, Chen JH, Zhong WD. MicroRNA-23b downregulates peroxiredoxin III in human prostate cancer. FEBS Lett. 2012, 586: 2451-2458.

[24] Li KK, Pang JC, Lau KM, Zhou L, Mao Y, Wang Y, Poon WS, Ng HK. MiR-383 is downregulated in medulloblastoma and targets peroxiredoxin 3 (PRDX3). Brain Pathol. 2013, 23: 
413-425.

[25] Shi L, Wu LL, Yang JR, Chen XF., Zhang Y, Chen ZQ, Liu CL, Chi SY, Zheng JY, Huang HX, Yu FJ, Lin XY. Serum peroxiredoxin3 is a useful biomarker for early diagnosis and assessment of prognosis of hepatocellular carcinoma in Chinese patients. Asian Pac J Cancer Prev. 2014;15:2979-2986.

[26] Ismail S, Mayah W, Battia HE, Gaballah H., Jiman-Fatani A, Hamouda H, Afifi MA, Elmashad N, Saadany SE. Plasma nuclear factor kappa B and serum peroxiredoxin 3 in early diagnosis of hepatocellular carcinoma. Asian Pac J Cancer Prev. 2015;16:1657-1663.

[27] Liu HL, Li TT, Yu AQ, Li J, Li X, Li L, Kaifu T. Plasma level of peroxiredoxin 3 in patients with polycystic ovarian syndrome. BMC Endocr Disord. 2019, 19(1): 32.

[28] Wang L, Hao JM, Yu AQ, Li TT, Liu RR, Li L, Li J, Li X. The association of plasma peroxiredoxin 3 with insulin in pregnant women. Biochem Biophys Res Commun. 2019, 508(3): 805-810. 
Figure legends:

Fig. 1. Representative results of immunohistochemistry for PRX3 and E6 of HPV16 or HPV18. A, PRX3 was extensively expressed in normal cervical epithelia. B, Intensive staining was observed in cervical cancer cells. C, Negative control of HPV16 E6 staining in normal cervical epithelia. D, The E6 of HPV16 was expressed in nearly all cervical cancer cells. E, Negative control of HPV18 E6 staining in normal cervical epithelia. F, The E6 of HPV18 was expressed in nearly all cervical cancer cells but the intensity was weaker than that of HPV16 E6. Scale bar=50 $\mu$ m; original magnification $\times 200$

Fig. 2. The expression of PRX3 and E6 as determined in cervical cancer cell lines. A, WB analysis for PRX3 indicated that the signals of CaSki and HeLa cells were much enhanced as compared to that of C33A cells. B, WB analysis for E6 of HPV16 and HPV18 in CaSki and HeLa cell lines, respectively. C, Analysis of variance showed higher expression of PRX3 in CaSki and HeLa cells than in C33A cells. (CaSki vs. C33A: $F=3.480, P=0.002 ;$ HeLa vs. C33A: $F=2.901, P=0.006$ ). 
Table 1 Comparison of clinical and biochemical data between cervical cancer patients and controls

\begin{tabular}{|c|c|c|c|c|c|c|c|c|c|}
\hline & \multirow{2}{*}{$\mathrm{n}$} & \multirow{2}{*}{ Age } & \multirow{2}{*}{ BMI } & \multicolumn{2}{|c|}{$\mathrm{BP}(\mathrm{mmHg})$} & \multirow{2}{*}{$\begin{array}{c}\text { FBS } \\
(\mathrm{mmoL} / \mathrm{L})\end{array}$} & \multirow{2}{*}{$\begin{array}{c}\text { FINS } \\
(\mathrm{mU} / \mathrm{L})\end{array}$} & \multirow{2}{*}{$\begin{array}{c}\mathrm{TC} \\
(\mathrm{mmoL} / \mathrm{L}) \\
\end{array}$} & \multirow{2}{*}{$\begin{array}{c}\mathrm{TG} \\
(\mathrm{mmoL} / \mathrm{L})\end{array}$} \\
\hline & & & & $\mathrm{SBP}^{2}$ & $\mathrm{DBP}^{3}$ & & & & \\
\hline $\mathrm{CC}^{1}$ & 56 & $47.6 \pm 5.8$ & $22.4 \pm 3.1$ & $119 \pm 7.5$ & $83 \pm 8.0$ & $4.8 \pm 1.5$ & $10.2 \pm 3.3$ & $4.8 \pm 0.9$ & $1.0 \pm 0.8$ \\
\hline Control & 60 & $46.8 \pm 3.5$ & $22.7 \pm 3.7$ & $121 \pm 5.4$ & $81 \pm 7.8$ & $5.1 \pm 1.5$ & $10.7 \pm 3.6$ & $5.2 \pm 0.9$ & $1.2 \pm 0.8$ \\
\hline$t$ value & & 1.515 & 1.436 & 1.401 & 1.319 & 0.185 & 1.510 & 1.445 & 1.850 \\
\hline$P$ value & & 0.136 & 0.172 & 0.167 & 0.193 & 0.853 & 0.131 & 0.155 & 0.064 \\
\hline
\end{tabular}

${ }^{1} \mathrm{CC}$ : cervical cancer; ${ }^{2} \mathrm{SBP}$ : systolic blood pressure; ${ }^{3} \mathrm{DBP}$ : diastolic blood pressure. 
Table 2 Association of staining scores of PRX3 or HPV16 E6 with clinicopathologic parameters

\begin{tabular}{cccccccc}
\hline & \multicolumn{2}{c}{ Stages } & \multicolumn{3}{c}{ Cell grades } & \multicolumn{2}{c}{ Lymph nodes } \\
\cline { 2 - 8 } & I & II & I & II & III & Positive & Negative \\
\hline Cases & 39 & 17 & 13 & 15 & 28 & 10 & 46 \\
PRX3 & & & & & & & \\
$(\mathrm{n}=56)$ & $9.8 \pm 1.4$ & $11.4 \pm 1.4$ & $12.2 \pm 1.6$ & $10.5 \pm 1.5$ & $9.5 \pm 1.2$ & $12.3 \pm 1.6$ & $8.9 \pm 1.2$ \\
$r$ & 0.247 & 0.207 & -0.417 & -0.352 & -0.383 & 0.32 & 0.313 \\
$P$ & 0.224 & 0.292 & 0.06 & 0.084 & 0.058 & 0.104 & 0.146 \\
HPV16 & $8.5 \pm 1.1$ & $9.6 \pm 1.5$ & $8.8 \pm 1.5$ & $9.1 \pm 1.1$ & $9.3 \pm 1.3$ & $9.6 \pm 1.4$ & $8.6 \pm 1.2$ \\
E6 (n=48) & & 0.170 & -0.325 & -0.372 & 0.393 & 0.296 & 0.192 \\
$r$ & 0.110 & 0.415 & 0.122 & 0.538 & 0.071 & 0.142 & 0.339 \\
$P$ & 0.593 & 0.415 &
\end{tabular}




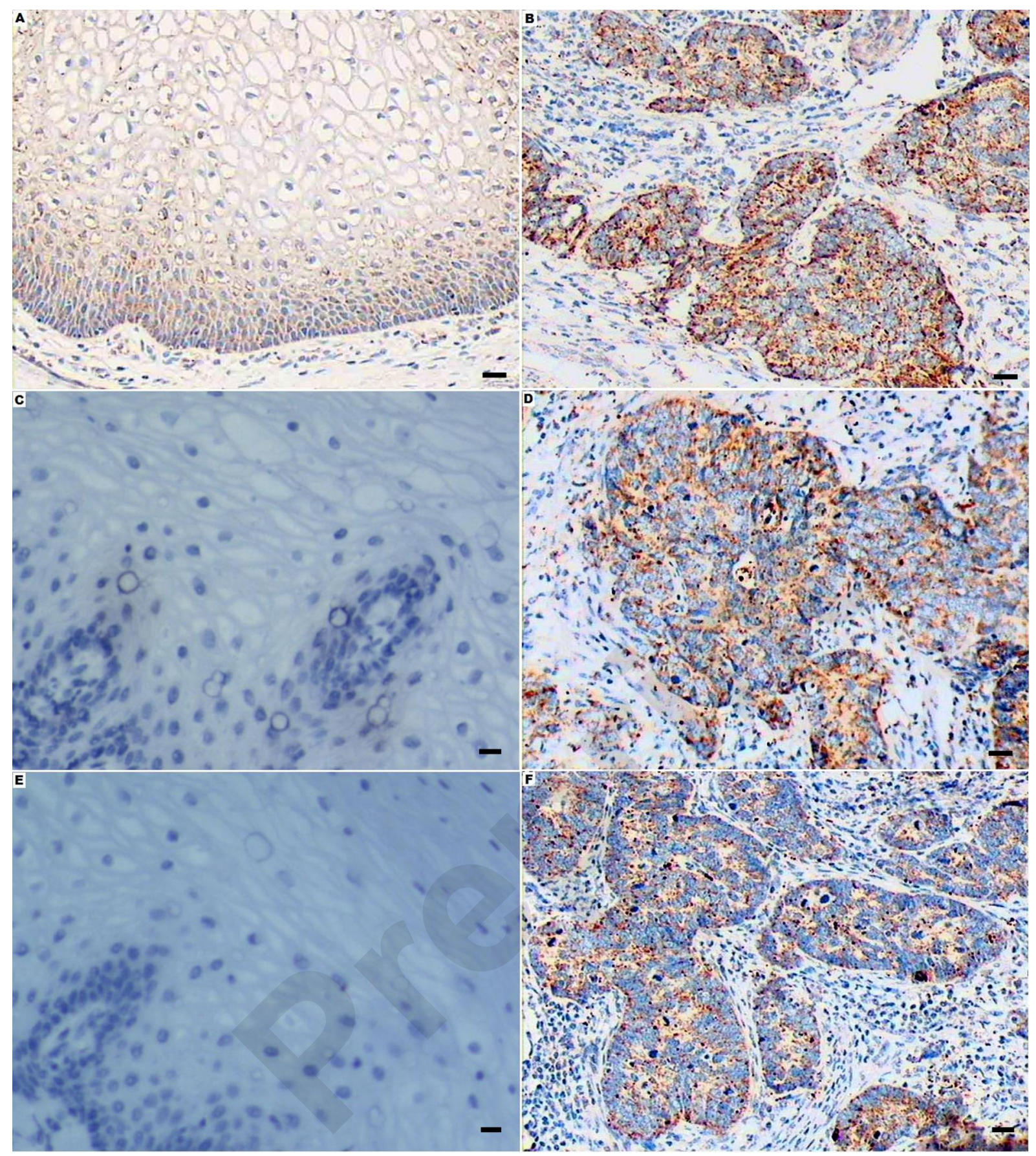




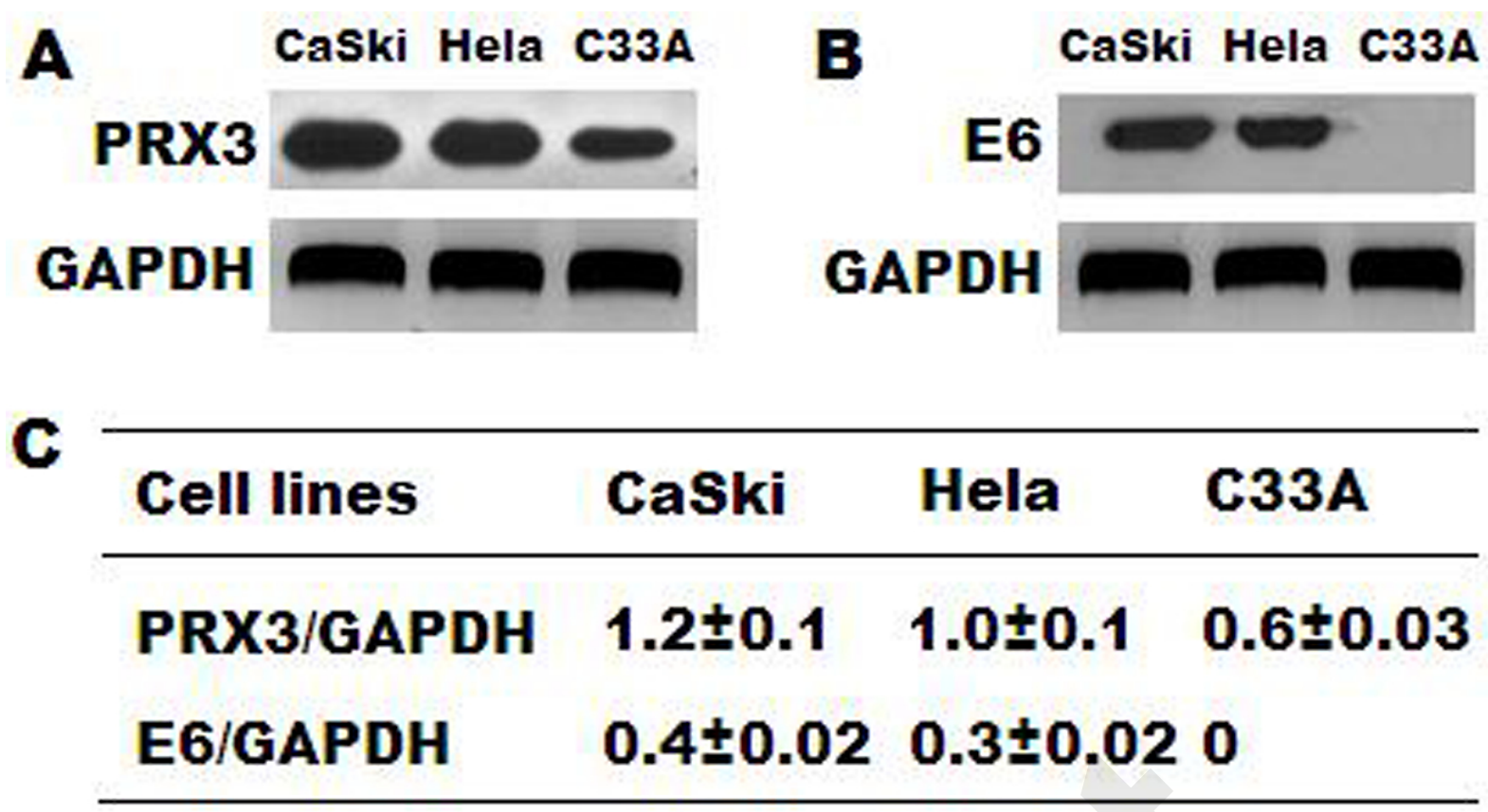

